\title{
Quantificação e modelagem dos macronutrientes em povoamentos de bracatinga
}

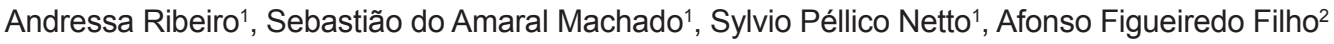 \\ ${ }^{1}$ Universidade Federal do Paraná, Departamento de Ciências Florestais, Av. Pref. Lothário Meissner, 632, CEP 80210-170, Curitiba, PR, Brasil. \\ 2 Universidade Estadual do Centro-Oeste, Departamento de Engenharia Florestal, PR-153 - Km 7, Riozinho, CEP 84500-000 - Irati, PR, Brasil.
}

\author{
"Autor correspondente: \\ andressa.florestal@gmail.com \\ Termos para indexação: \\ Área basal \\ Modelos matemáticos \\ Povoamento florestal \\ Index terms: \\ Basal area \\ Mathematical models \\ Forest stands
}

Histórico do artigo:

Recebido em 19 out 2011

Aprovado em 29 fev 2012

Publicado em 30 mar 2012

doi: 10.4336/2012.pfb.32.69.29
Resumo - A quantificação dos nutrientes em ecossistemas florestais é fundamental para verificação da manutenção do fluxo contínuo entre o que é depositado no solo e o que é assimilado novamente pelas plantas. O uso da área basal como ferramenta prática na medição dos povoamentos florestais, faz com que a modelagem no âmbito dos povoamentos seja facilmente aplicável à quantificação de nutrientes. Assim, o presente trabalho teve como objetivo quantificar e modelar o peso de macronutrientes por hectare nos diferentes compartimentos aéreos. Os dados utilizados foram coletados em 304 parcelas temporárias com diferentes idades em povoamentos de bracatinga (Mimosa scabrella Bentham.), localizados na região metropolitana de Curitiba. Foram avaliados 23 modelos matemáticos para cada compartimento aéreo, dos quais, apenas um modelo por compartimento para todos os macronutrientes foi selecionado e validado, se mostrando apropriado para estimativa dos nutrientes por hectare. Em ordem decrescente, os valores de macronutrientes encontrados na parte aérea dos bracatingais seguiram a sequência de $\mathrm{N}>\mathrm{Ca}>\mathrm{K}>\mathrm{Mg}>\mathrm{P}$. Após a exploração da lenha, restaram na área os resíduos contendo $25 \%$ de Ca, $32 \%$ de $\mathrm{Mg}, 37 \%$ de N, $45 \%$ de $\mathrm{P}$ e $18 \%$ de $\mathrm{K}$.

\section{Quantification and modeling of macronutrients in bracatinga stands}

\begin{abstract}
Quantification of nutrients in forest ecosystems is fundamental for the verification of the maintenance of continuous flow between what is deposited in the soil and what is re-assimilated by the plants. Using basal area as a practical tool in the measurement of forest stands makes modeling easy at stand level for nutrient quantification. Thus, the present work had as objective to quantify and fit the weight of macronutrients per hectare in different compartments of above ground biomass. The data used in this research came from 304 temporary plots with different ages in Mimosa scabrella Bentham. (bracatinga) stands located in the metropolitan region of Curitiba. Twenty three mathematical models were evaluated. Only one model was selected and validateds and it was appropriate for the estimation of nutrients quantities per hectare found in above ground of bracatinga biomass. In decrease order, the estimated values of macronutrients found in the aerial parts of bracatinga stands followed the sequence of $\mathrm{N}>\mathrm{Ca}>\mathrm{K}>\mathrm{Mg}>\mathrm{P}$. After the exploitation of fire wood, were left as remnants in the area $25 \%$ of $\mathrm{Ca}, 32 \%$ of $\mathrm{Mg}, 37 \%$ of $\mathrm{N}, 45 \%$ of $\mathrm{P}$ and $18 \%$ of $\mathrm{K}$.
\end{abstract}




\section{Introdução}

O sistema de manejo da bracatinga é, de certa forma, simplificado e realizado pela maioria dos produtores de forma empírica. Segundo Carneiro et al. (1982), no manejo é feito uma roçada para limpeza da área, visando facilitar o corte da bracatinga, que geralmente ocorre entre cinco a dez anos de idade, na forma de corte raso. Após o corte, é prática usual a queima dos resíduos da exploração para que ocorra a quebra de dormência das sementes acumuladas em diferentes camadas do solo e a consequente regeneração natural da floresta. Passados cem anos de cultivo, os tratos culturais continuam poucos, a reposição de nutrientes por adubação é ínfima e nenhum material genético apropriado para o sistema foi desenvolvido (Carpanezzi, 2006), gerando opiniões diversas sobre o manejo e sua sustentabilidade na produção dos bracatingais.

As explorações intensivas em rotações curtas, sem previsão de um período mínimo necessário para reposição de nutrientes, têm sido apontadas como as maiores responsáveis pela exaustão do solo (Ferreira et al., 2001). Esses autores ainda apontam a inconveniência da exploração total da árvore e a importância da manutenção das galhadas e folhas no campo. Schumacher \& Caldeira (2001) destacaram a relevância em se quantificar a biomassa e os nutrientes produzidos pela floresta para determinação do que é exportado do ambiente quando ocorre a exploração. Vieira et al. (2011) afirmaram que para avaliar práticas de manejo tanto em ecossistemas de florestas plantadas quanto naturais, o estudo da biomassa e de nutrientes removidos com a colheita florestal configura-se como um fator essencial em favor do uso sustentado desses ecossistemas.

Diversos trabalhos foram desenvolvidos com o intuito de modelagem e quantificação dos nutrientes em componentes da biomassa florestal (Bellote et al., 1980; Baggio \& Carpanezzi, 1997; Schumacher \& Caldeira, 2001; Caldeira et al., 2002; Schumacher et al., 2008, Téo et al., 2010) para embasar atividades silviculturais e reposição de nutrientes. Porém os modelos utilizados nestes trabalhos envolviam apenas variáveis dendrométricas individuais, resultando na estimativa individual do conteúdo de nutrientes por árvore para posterior extrapolação do conteúdo de nutrientes por unidade de área.
Assim, para auxílio na inferência sobre a conveniência do manejo da bracatinga sobre o ponto de vista nutricional, a modelagem dos nutrientes por unidade de área reduz significativamente o número de variáveis a serem coletadas em campo, pois, as equações formuladas geralmente incluem variáveis que expressam a densidade de um povoamento, tais como área basal, número de indivíduos, altura dominante, altura média, idade, índice de sítio, diâmetro médio e diâmetro médio quadrático.

A amostragem por pontos, utilizando o princípio de Bitterlich, para estimativa de área basal de povoamentos florestais é um método simples de ser aplicado em campo e baseado em uma teoria bastante sólida, tendo sido utilizado por algumas instituições com sucesso (Couto et al., 1993).

Deste modo, o presente trabalho propõe uma abordagem distinta para quantificar os nutrientes presentes na biomassa aérea total da árvore e nos compartimentos lenha e copa, utilizando dados provenientes de diferentes povoamentos de bracatinga, a fim de modelar a quantidade de macronutrientes por unidade de área.

\section{Material e métodos}

\section{Caracterização da área e da base de dados}

Os dados dos bracatingais foram coletados em 15 municípios, abrangendo uma área de influência de 731.850 ha dentro da região metropolitana de Curitiba, localizada no primeiro planalto do estado do Paraná. A unidade fitogeográfica onde os dados foram coletados é caracterizada como sendo transicional entre a Floresta Ombrófila Densa e a Floresta Ombrófila Mista.

O clima do primeiro planalto do Paraná, de acordo com a classificação de Köeppen, é o Cfb, com temperatura média anual de $16,5^{\circ} \mathrm{C}$, temperatura média do mês mais quente de $20,4^{\circ} \mathrm{C}$ e do mês mais frio de $12,7^{\circ} \mathrm{C}$. O mês mais chuvoso é janeiro, com 190,7 mm, e o mais seco é o mês de agosto, com 78,2 mm; a precipitação anual média fica em torno de $1.500 \mathrm{~mm}$ (Maack, 2002). Os bracatingais estão inseridos em solos do tipo: Latossolo Roxo Álico e Distrófico, Latossolo Vermelho-Escuro Álico e Distrófico, Latossolo Vermelho-Amarelo Álico pouco profundo, Podzólico Vermelho-Amarelo Álico, Cambissolo Álico e Distrófico e Solos Litólicos Álicos e Distróficos (Embrapa, 1984). 
Para o ajuste dos modelos matemáticos referentes aos compartimentos lenha, copa e biomassa aérea total, foram utilizadas 304 parcelas temporárias de tamanho variável (96 a $415 \mathrm{~m}^{2}$ ), com idade entre 3 a 18 anos, em três diferentes classes de sítio com idade de referência de sete anos ( 9 m, $13 \mathrm{~m}$ e $17 \mathrm{~m}$ ), com diâmetro a 1,30 $\mathrm{m}$ do solo (DAP) mínimo de $3,7 \mathrm{~cm}$ e máximo de 23,4 $\mathrm{cm}$, e altura mínima de $6,9 \mathrm{~m}$ e máxima de 20,2 m. Do total das parcelas, 43 constituíram uma base de dados para validação das equações por povoamentos selecionados, pois é necessário utilizar uma base de dados independente do ajuste para proceder a validação (Vanclay \& Skovsgaard, 1997).

Em todas as parcelas foram medidas as circunferências a altura do peito (CAP) e altura total de todos os indivíduos. Utilizou-se para a medição do CAP das árvores uma fita métrica e para altura total um hipsômetro Blume-Leiss ou uma vara métrica graduada. A idade foi determinada a partir de informações locais, ou, na ausência dessas, pela contagem dos anéis de crescimento.

\section{Modelagem individual dos nutrientes}

As estimativas dos nutrientes da biomassa aérea total e no compartimento lenha das árvores individuais foram realizadas utilizando as equações desenvolvidas por Téo (2009) em trabalho realizado para quantificação dos nutrientes em árvores de bracatinga. A biomassa aérea total foi considerada como a soma do peso seco dos compartimentos fuste, casca, galhos com diâmetro menor que $4 \mathrm{~cm}$, galhos com diâmetro maior ou igual a $4 \mathrm{~cm}$, galhos mortos e folhas. Já o compartimento lenha foi definido como sendo o peso seco dos componentes fuste, casca e galhos com diâmetro maior ou igual a 4 $\mathrm{cm}$. O resultado da subtração entre as estimativas da biomassa total e a lenha resultou na copa (galhos $<4$ $\mathrm{cm}$, folhas e galhos mortos), a qual permanece na área após a exploração do bracatingal.

As equações utilizadas por Téo (2009) foram ajustadas na presente base de dados (304 parcelas), contendo 14.032 árvores; todos os ajustes foram realizados por meio da aplicação de regressão linear pelo método dos mínimos quadrados. Foram testados os quinze modelos utilizados pelo autor, entre os quais o modelo que mais se adequou aos dados do presente estudo foi o de Brenac $\left(\ln (\mathrm{Y})=\beta_{0}+\beta_{1} \cdot \ln (\mathrm{DAP})+\beta_{2} \cdot 1 / \mathrm{DAP}\right)$ para todos os nutrientes. Os coeficientes das equações e as estatísticas de precisão dos ajustes individuais estão listados na Tabela 1.

\section{Modelagem dos nutrientes por unidade de área}

Após a modelagem individual, as estimativas de nutrientes por unidade de área foram feitas seguindo o processamento usual de um inventário florestal. De posse das estimativas advindas dos modelos individuais aplicados às árvores contidas nas 304 parcelas, os pesos dos nutrientes presentes em cada parcela foram somados, resultando em um valor em quilogramas por parcela. Esse valor foi extrapolado para hectare, conforme a área amostral de cada parcela, o que resultou nos valores de nutrientes por hectare em cada uma delas. Estes valores, por sua vez, serviram como variável dependente para a nova modelagem por unidade de área nas 261 parcelas utilizadas para os ajustes.

Os modelos testados foram selecionados na literatura,

Tabela 1.Coeficientes das equações e respectivas estatísticas de Brenac, conforme Téo (2009), para os compartimentos: total e lenha

\begin{tabular}{ccccccc}
\hline \multirow{2}{*}{ Nutriente } & Componente & $\mathbf{B}_{\mathbf{0}}$ & $\mathbf{B}_{\mathbf{1}}$ & $\mathbf{B}_{\mathbf{2}}$ & $\mathbf{R}_{\mathbf{a j}}^{\mathbf{2}}(\mathbf{\%})$ & $\mathbf{S}_{\mathbf{y x}} \mathbf{( \% )}$ \\
\hline \multirow{2}{*}{$\mathrm{N}$} & Total & 8,39497 & $-0,08425$ & $-26,84550$ & 91,16 & 20,08 \\
& Lenha & 6,01504 & 0,51266 & $-22,19480$ & 92,28 & 20,08 \\
\multirow{2}{*}{$\mathrm{P}$} & Total & 5,53845 & $-0,29330$ & $-27,52100$ & 80,31 & 29,9 \\
& Lenha & 3,56072 & 0,10189 & $-23,09340$ & 77,58 & 32,56 \\
\multirow{2}{*}{$\mathrm{K}$} & Total & 9,15311 & $-0,48628$ & $-32,49350$ & 58,28 & 58,69 \\
& Lenha & 8,02630 & $-0,20646$ & $-29,94640$ & 56,11 & 62,83 \\
\multirow{2}{*}{$\mathrm{Ca}$} & Total & 10,71795 & $-0,96967$ & $-36,0036$ & 91,74 & 17,66 \\
& Lenha & 11,05354 & $-1,11159$ & $-39,1990$ & 91,39 & 18,91 \\
$\mathrm{Mg}$ & Total & $-2,11787$ & 2,12382 & $-2,12617$ & 67,85 & 45,45 \\
& Lenha & $-4,55113$ & 2,74937 & 2,84901 & 57,28 & 56,53 \\
\hline
\end{tabular}


em trabalhos científicos tradicionalmente conduzidos para estimativa volumétrica por unidade de área. Esses consistiram em diversos modelos aritméticos, semilogarítmicos e logarítmicos. Novamente, os ajustes foram feitos utilizando o método dos mínimos quadrados para todos os modelos, com exceção dos modelos 6 e 7 (não lineares), que tiveram seus parâmetros estimados pela função solver do excell ${ }^{\circledR}$, utilizando o algoritmo linear de gradiente reduzido generalizado (GRG) a fim de minimizar a soma de quadrado dos resíduos. Na Tabela 2 estão listados os modelos que foram utilizados no ajuste de nutrientes por hectare.

\section{Seleção dos modelos e validação das equações}

A seleção do melhor modelo para as estimativas das variáveis dependentes foi feita comparando cada modelo com suas estatísticas de precisão, ajuste e dispersão dos resíduos. Para tal, os critérios utilizados foram o coeficiente de determinação ajustado em porcentagem $\left(\mathrm{R}_{\text {aj }}^{2}\right)$, erro padrão da estimativa em quilos por hectare e percentual $\left(\mathrm{S}_{\mathrm{yx}}\right.$ e $\left.\mathrm{S}_{\mathrm{yx}} \%\right)$, significância dos coeficientes da equação (valor de $\mathrm{p}<0,05$ ) e análise visual dos gráficos de resíduos. Para os modelos matemáticos logarítmicos o fator de Meyer (FM) foi utilizado para correção da discrepância logarítmica. A soma de quadrados dos resíduos foi utilizada como critério de desempate entre os modelos selecionados, considerando que, quanto menor o valor da soma de quadrado dos resíduos, melhor a estimativa gerada pelo modelo (Draper \& Smith, 1968).

No caso de alguns modelos, nos quais a variável dependente sofreu alguma transformação, o $\mathrm{S}_{\mathrm{yx}}$ foi retransformado, calculando-se a variável dependente estimada na unidade da variável observada. Todos os

Tabela 2. Modelos matemáticos avaliados.

\begin{tabular}{|c|c|c|}
\hline Modelo & Estrutura Matemática & Autor \\
\hline 1 & $\mathrm{Y}=\beta_{0}+\beta_{1 .} \mathrm{G}+\varepsilon$ & Spurr (1952) \\
\hline 2 & $Y=\beta_{0}+\beta_{1 .} G \bar{h}+\varepsilon$ & Spurr (1952) \\
\hline 3 & $\mathrm{Y}=\beta_{0}+\beta_{1} \mathrm{G} \mathrm{h}_{\mathrm{dom}}+\varepsilon$ & Spurr (1952) \\
\hline 4 & $\mathrm{Y}=\beta_{0}+\beta_{1 .} \mathrm{G}^{2} \overline{\mathrm{h}}+\varepsilon$ & Rosot (1989) \\
\hline 5 & $\mathrm{Y}=\beta_{0}+\beta_{1 .} \mathrm{G}^{2} \mathrm{~h}_{\mathrm{dom}}+\varepsilon$ & Silva (1979) \\
\hline 6 & $\mathrm{Y}=\beta_{0}+\mathrm{G}^{\beta 1}+\overline{\mathrm{h}}^{\beta 2}+\mathcal{E}$ & Ung \& Ouellet (1991) \\
\hline 7 & $\mathrm{Y}=\beta_{0}+\mathrm{G}^{\beta 1}+\mathrm{h}_{\mathrm{dom}}{ }^{\beta 2}+\mathcal{E}$ & Ung \& Ouellet (1991) \\
\hline 8 & $Y=\beta_{0}+\beta_{1} \ln (G \bar{h})+\varepsilon$ & Figueiredo Filho (1983) \\
\hline 9 & $\mathrm{Y}=\beta_{0}+\beta_{1} \ln \left(\mathrm{G} \mathrm{h}_{\mathrm{dom}}\right)+\varepsilon$ & Figueiredo Filho (1983) \\
\hline 10 & $\mathrm{Y}=\beta_{0}+\beta_{1} \ln \left(\mathrm{G}^{2} \overline{\mathrm{h}}\right)+\varepsilon$ & Figueiredo Filho (1983) \\
\hline 11 & $\ln Y=\beta_{0}+\beta_{1} \ln (G)+\varepsilon$ & Spurr (1952) \\
\hline 12 & $\ln Y=\beta_{0}+\beta_{1} \ln (G \bar{h})+\varepsilon$ & Spurr (1952) \\
\hline 13 & $\ln Y=\beta_{0}+\beta_{1} \ln \left(\mathrm{G} \mathrm{h}_{\mathrm{dom}}\right)+\varepsilon$ & Spurr (1952) \\
\hline 14 & $\ln Y=\beta_{0}+\beta_{1} \ln \left(G^{2} \bar{h}\right)+\varepsilon$ & Figueiredo Filho (1983) \\
\hline 15 & $\ln Y=\beta_{0}+\beta_{1} \ln \left(\mathrm{G}^{2} \mathrm{~h}_{\mathrm{dom}}\right)+\varepsilon$ & Spurr (1952) \\
\hline 16 & $\ln Y=\beta_{0}+\beta_{1} \ln (G \bar{h})+\beta_{2} \ln \left(G h_{\text {dom }}\right)+\varepsilon$ & Profumo Aguiar (2006) \\
\hline 17 & $\ln \mathrm{Y}=\beta_{0}+\beta_{1} \ln (\mathrm{GN})+\mathcal{E}$ & Rosot (1989) \\
\hline 18 & $\ln Y=\beta_{0}+\beta_{1} \ln \left(G^{2} N\right)+\varepsilon$ & Scolforo (2005) \\
\hline 19 & $\ln \mathrm{Y}=\beta_{0}+\beta_{1} \ln \left(\overline{\mathrm{d}}^{2} \overline{\mathrm{h}}\right)+\varepsilon$ & Rosot (1989) \\
\hline 20 & $\ln Y=\beta_{0}+\beta_{1} \ln (\mathrm{N} \overline{\mathrm{d}})+\varepsilon$ & Scolforo (2005) \\
\hline 21 & $\ln Y=\beta_{0}+\beta_{1} \cdot S+\beta_{2} I^{-1}+\beta_{3} \cdot \ln (G)+\varepsilon$ & Sullivan \& Clutter (1972) \\
\hline 22 & $\ln Y=\beta_{0}+\beta_{1} \cdot \ln (G)+\beta_{2} \cdot \ln (\bar{h})+\varepsilon$ & Ung \& Ouellet log. (1991) \\
\hline 23 & $\ln Y=\beta_{0}+\beta_{1} \cdot \ln (\mathrm{G})+\beta_{2} \cdot \ln \left(\mathrm{h}_{\mathrm{dom}}\right)+\varepsilon$ & Ung \& Ouellet log. (1991) \\
\hline
\end{tabular}

Em que: $\ln =$ logaritmo natural, $Y=$ variável dependente (conteúdo de macronutrientes em $\left.\mathrm{kg} \mathrm{ha}^{-1}\right), \mathrm{G}=$ área basal $\left(\mathrm{m}^{2} \mathrm{ha}^{-1}\right), \overline{\mathrm{h}}=\mathrm{altura}$ média $(\mathrm{m}), \mathrm{h}_{\text {dom }}=\mathrm{altura}$ dominante média (m), $\overline{\mathrm{d}}=$ diâmetro médio $(\mathrm{cm})$ e $\mathrm{N}=$ número de indivíduos por hectare. 
cálculos das estatísticas de precisão dos ajustes seguiram a formulação sugerida por Scolforo (2005).

Os gráficos de resíduos foram plotados conforme Montgomery \& Peck (1992), que sugeriram a utilização dos valores estimados na abscissa, devido ao fato desses não possuírem correlação com os resíduos, ao contrário dos valores observados, que são usualmente correlacionados. Os valores de resíduos foram utilizados em porcentagem contra os valores estimados de cada macronutriente.

Para validação das equações selecionadas, foi extraída uma base de dados independente contendo 43 parcelas distribuídas proporcionalmente nas classes diamétricas (seis classes com amplitude de 3,3 cm) avaliadas e correspondendo a aproximadamente $15 \%$ do total de parcelas amostradas. A validação foi feita conforme sugerido por Soares et al. (1995), que fizeram o uso da acurácia e precisão para avaliar o comportamento dos modelos selecionados. A análise visual dos gráficos de resíduos também foi feita juntamente com o cálculo das estatísticas. As formulações para obtenção da acurácia e da precisão, nas quais, a primeira é expressa pelo resíduo médio e a segunda pelo resíduo médio absoluto, estão expressas na Tabela 3 .

Tabela 3. Fórmulas para cálculo de acurácia e precisão para validação das equações selecionadas.

\section{Resíduo Médio Resíduo Médio (\%)}

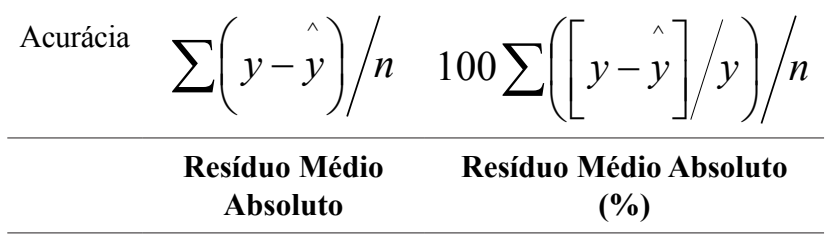

Precisão

$$
\sum|y-\hat{y}| / n \quad 100 \sum(|y-\hat{y}| / y) / n
$$

Em que: $y=$ variável dependente estimada, $\mathrm{y}=$ variável dependente observada e $\mathrm{n}=$ número de observações.

\section{Resultados e discussão}

As estatísticas descritivas das principais variáveis coletadas nas 304 parcelas utilizadas no estudo estão listadas na Tabela 4. Percebe-se que a maior variação ocorreu no número de indivíduos, idade e na área basal. Tal fato é explicado pela variabilidade na idade das parcelas e na grande influência dessa variável no ciclo de vida do bracatingal. Sendo uma espécie pioneira e heliófila, a tendência é diminuir o número de indivíduos e, consequentemente, a área basal, à medida que o povoamento envelhece.

Aguiar (2006), ao estudar uma base de dados semelhante ao do presente trabalho, também encontrou grandes variações nas mesmas variáveis apontadas, sendo tal fato consequência da grande discrepância nas densidades iniciais que ocorreram nas diversas parcelas que compõe a base de dados.

Dos 23 modelos avaliados apresentados na Tabela 2, os de pior desempenho foram os que não utilizaram área basal como variável independente, tais como o modelo 19 e 20; para a maioria dos macronutrientes os mesmos modelos não apresentaram significância estatística no valor de p para os coeficientes da regressão. Os melhores modelos foram aqueles que tiveram a combinação de área basal e altura média e/ou dominante (modelos 22 e 14), ou apenas a área basal (modelo 11), no caso dos modelos de copa. Machado et al. (2008), testando diversos modelos para estimar o volume por unidade de área em bracatingais da região metropolitana de Curitiba, encontraram resultados de alta correlação das

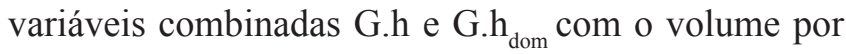
hectare, coeficientes de correlação simples de 0,998 e 0,987, respectivamente, ressaltando ainda que apenas a variável área basal apresentou uma forte correlação com o volume total $(\mathrm{r}=0,837)$.

Os valores das estatísticas de precisão e ajuste dos 23 modelos avaliados estão listados nas tabelas 5, 6 e 7 para biomassa aérea total, compartimento lenha e copa, respectivamente. Nota-se que os valores de $\mathrm{R}_{\text {aj }}^{2}$ para o modelo 19 foi sempre abaixo de $5 \%$, sendo esse igual a zero ou mesmo negativo para a maioria dos macronutrientes avaliados. Como dito anteriormente, a significância estatística do coeficiente angular deste modelo não ocorreu, acarretando na estimativa apenas da média. Soares et al. (1995), ao apresentarem uma estatística análoga ao $\mathrm{R}^{2}$ denominada eficiência do modelo, afirmaram que valores iguais a zero indicam que o modelo não acrescenta qualquer melhora e se equivale à média aritmética da variável dependente, e valores negativos revelam um modelo naturalmente ruim. Silva et al. (2008) ao estudarem os cuidados que se deve ter 
ao empregar o $\mathrm{R}^{2}$ como estatística de precisão, também afirmaram que o coeficiente de determinação pode ser igual a zero ou até mesmo negativo, caso o intercepto do modelo gerado pelo método dos mínimos quadrados não seja significativo, acarretando num modelo mal especificado.

Tabela 4. Estatísticas descritivas das principais variáveis independentes analisadas.

\begin{tabular}{ccccccc}
\hline Variável & Mínimo & Máximo & Média & Desvio Padrão & Variância & CV (\%) \\
\hline DAP (cm) & 3,67 & 23,45 & 10,77 & 3,85 & 14,85 & 35,96 \\
H (m) & 6,91 & 20,18 & 12,43 & 2,65 & 7,03 & 21,32 \\
G (m².ha- $\left.{ }^{1}\right)$ & 2,04 & 56,01 & 13,07 & 6,36 & 40,43 & 47,21 \\
Hdom (m) & 7,50 & 21,33 & 13,79 & 2,83 & 8,01 & 20,67 \\
N (ind.ha- $\left.{ }^{-}\right)$ & 67 & 12.439 & 1.997 & 1.930 & 3.724 .489 & 97,55 \\
Idade (anos) & 3,00 & 18,00 & 8,89 & 3,64 & 13,25 & 41,43 \\
\hline
\end{tabular}

Tabela 5. Estatísticas de ajuste e precisão dos modelos ajustados por hectare para a biomassa total da aérea de povoamentos de bracatinga.

\begin{tabular}{|c|c|c|c|c|c|c|c|c|c|c|c|c|c|c|c|}
\hline \multirow[b]{3}{*}{ Modelos } & \multicolumn{15}{|c|}{ Macronutrientes } \\
\hline & \multicolumn{3}{|c|}{$\mathrm{Ca}$} & \multicolumn{3}{|c|}{ Mg } & \multicolumn{3}{|c|}{$\mathbf{N}$} & \multicolumn{3}{|c|}{$\mathbf{P}$} & \multicolumn{3}{|c|}{$\mathbf{K}$} \\
\hline & Syx & Syx\% & $\mathbf{R}_{\mathrm{aj}}^{2}$ & Syx & Syx\% & $\mathbf{R}_{\text {aj }}^{2}$ & Syx & Syx\% & $\mathbf{R}_{\mathrm{aj}}^{2}$ & Syx & Syx\% & $\mathbf{R}_{\text {aj }}^{2}$ & Syx & Syx\% & $\mathbf{R}^{2}{ }_{\text {aj }}$ \\
\hline 1 & 33,1 & 18,3 & 87,3 & 4 & 20,6 & 81,9 & 60,6 & 16,8 & 89,1 & 1,8 & 15,3 & 90,6 & 33,3 & 19,4 & 86,3 \\
\hline 2 & 42,2 & 23,3 & 79,3 & 0,7 & 3,8 & 99,4 & 73,5 & 20,4 & 84,1 & 2,6 & 22,1 & 80,5 & 36,1 & 21,1 & 83,8 \\
\hline 3 & 43,4 & 24 & 78,1 & 1,3 & 6,6 & 98,1 & 77,2 & 21,4 & 82,4 & 2,6 & 22,5 & 79,7 & 38,4 & 22,4 & 81,7 \\
\hline 4 & 46 & 25,4 & 75,4 & 4,6 & 23,3 & 76,9 & 81,9 & 22,7 & 80,2 & 2,8 & 23,8 & 77,4 & 40,8 & 23,8 & 79,3 \\
\hline 5 & 46,1 & 25,5 & 75,3 & 4,6 & 23,4 & 76,8 & 82,7 & 23 & 79,8 & 2,8 & 23,8 & 77,4 & 41,4 & 24,1 & 78,8 \\
\hline 6 & 39,3 & 21,7 & 82,1 & 1,8 & 9 & 96,5 & 76,9 & 21,4 & 82,5 & 1,7 & 14,5 & 91,6 & 35,1 & 20,5 & 84,7 \\
\hline 7 & 39,4 & 21,8 & 82 & 1,9 & 9,6 & 96 & 77 & 21,4 & 82,5 & 1,7 & 14,9 & 91,1 & 35,5 & 20,7 & 84,4 \\
\hline 8 & 55 & 30,4 & 65 & 3,8 & 19,3 & 84,1 & 105,2 & 28,9 & 67,3 & 3,4 & 29,2 & 65,8 & 51,8 & 30,2 & 66,7 \\
\hline 9 & 56,6 & 31,3 & 62,8 & 3,9 & 20 & 83 & 108,8 & 29,9 & 65 & 3,5 & 29,9 & 64,2 & 53,8 & 31,4 & 64,1 \\
\hline 10 & 50,1 & 27,7 & 70,8 & 4,2 & 21,3 & 80,7 & 97 & 26,5 & 72,2 & 3 & 26,1 & 72,9 & 48,8 & 28,5 & 70,4 \\
\hline 11 & 33,4 & 18,5 & 87 & 4 & 20,6 & 82 & 62,3 & 17,3 & 88,5 & 1,8 & 15,5 & 90,4 & 34,3 & 20 & 85,4 \\
\hline 12 & 42,9 & 23,7 & 78,6 & 0,7 & 3,8 & 99,4 & 75,8 & 21 & 83,1 & 2,6 & 22,5 & 79,8 & 37,2 & 21,7 & 82,8 \\
\hline 13 & 44,5 & 24,6 & 77,5 & 1,3 & 6,7 & 98,1 & 80,7 & 22,4 & 80,8 & 2,7 & 23,2 & 78,5 & 40,1 & 23,4 & 80,1 \\
\hline 14 & 32,1 & 17,7 & 88 & 2 & 10,5 & 95,3 & 54,4 & 15,1 & 91,3 & 1,8 & 15,5 & 90,4 & 29 & 16,9 & 89,6 \\
\hline 15 & 34,6 & 19,1 & 86,1 & 2,3 & 11,5 & 94,4 & 60,2 & 16,7 & 89,3 & 1,9 & 16,7 & 88,9 & 31,9 & 18,6 & 87,3 \\
\hline 16 & 43 & 23,7 & 78,5 & 0,5 & 2,7 & 99,7 & 53,9 & 15 & 91,4 & 1,8 & 15,5 & 90,4 & 37,5 & 21,9 & 82,5 \\
\hline 17 & 76,5 & 42,3 & 31,9 & 8,3 & 42,4 & 23,3 & 154,2 & 42,8 & 29,8 & 4,7 & 40,1 & 35,6 & 77,1 & 45 & 26,1 \\
\hline 18 & 66,6 & 36,8 & 48,4 & 7,4 & 37,9 & 38,9 & 134,9 & 37,5 & 46,3 & 4 & 34,4 & 52,7 & 68,4 & 39,9 & 41,9 \\
\hline 19 & 93 & 51,4 & $-0,4$ & 9,3 & 47,5 & 4,1 & 184 & 51,1 & 0 & 5,8 & 50,2 & $-0,7$ & 89,5 & 52,1 & 0,7 \\
\hline 20 & 76 & 42 & 32,9 & 8,3 & 42,4 & 23,5 & 153,3 & 42,6 & 30,6 & 4,6 & 39,8 & 36,7 & 76,8 & 44,7 & 26,9 \\
\hline 21 & 32 & 17,7 & 88,1 & 2,2 & 11,2 & 94,7 & 53,3 & 14,8 & 91,6 & 1,7 & 14,6 & 91,4 & 29,2 & 17 & 89,4 \\
\hline 22 & 31,1 & 17,2 & 88,7 & 0,7 & 3,6 & 99,4 & 54,4 & 15,1 & 91,3 & 1,7 & 14,4 & 91,7 & 29,5 & 17,2 & 89,2 \\
\hline 23 & 32,4 & 17,9 & 87,8 & 1,3 & 6,6 & 98,1 & 58,7 & 16,3 & 89,8 & 1,8 & 15,1 & 90,9 & 31,8 & 18,5 & 87,4 \\
\hline
\end{tabular}

Em que: $\mathrm{S}_{\mathrm{yx}}$ e $\mathrm{S}_{\mathrm{yx}} \%$ = significância dos coeficientes da equação e $\mathrm{R}_{\mathrm{aj}}^{2}=$ erro padrão da estimativa em quilos por hectare e percentual. 
Tabela 6. Estatísticas de ajuste e precisão dos modelos ajustados por hectare para a biomassa lenha da aérea de povoamentos de bracatinga.

\begin{tabular}{|c|c|c|c|c|c|c|c|c|c|c|c|c|c|c|c|}
\hline \multirow[b]{3}{*}{ Modelos } & \multicolumn{15}{|c|}{ Macronutrientes } \\
\hline & \multicolumn{3}{|c|}{$\mathrm{Ca}$} & \multicolumn{3}{|c|}{ Mg } & \multicolumn{3}{|c|}{$\mathbf{N}$} & \multicolumn{3}{|c|}{$\mathbf{P}$} & \multicolumn{3}{|c|}{ K } \\
\hline & Syx & Syx\% & $\mathbf{R}_{\text {aj }}^{2}$ & Syx & Syx \% & $\mathbf{R}_{\text {aj }}^{2}$ & Syx & Syx\% & $\mathbf{R}_{\text {aj }}^{2}$ & Syx & Syx\% & $\mathbf{R}_{\text {aj }}^{2}$ & Syx & Syx \% & $\mathbf{R}_{\mathrm{aj}}^{2}$ \\
\hline 1 & 27,3 & 20,3 & 85 & 2,7 & 20,6 & 81,9 & 42,9 & 19,3 & 86,7 & 0,9 & 14 & 92,1 & 27,6 & 19,8 & 85,5 \\
\hline 2 & 30,8 & 23 & 80,9 & 0,5 & 3,8 & 99,4 & 40,2 & 18 & 88,3 & 1,3 & 21 & 82,1 & 28,1 & 20,1 & 85,5 \\
\hline 3 & 32,2 & 24 & 79,1 & 0,9 & 6,6 & 98,1 & 44,8 & 20,1 & 85,4 & 1,4 & 21,5 & 81,3 & 30,4 & 21,7 & 83 \\
\hline 4 & 34,2 & 25,5 & 76,4 & 3,1 & 23,3 & 76,9 & 47,5 & 21,3 & 83,7 & 1,4 & 22,7 & 79,2 & 32,3 & 23,1 & 80,8 \\
\hline 5 & 34,5 & 25,7 & 76 & 3,1 & 23,4 & 76,8 & 48,8 & 21,9 & 82,7 & 1,4 & 22,7 & 79,2 & 32,9 & 23,5 & 80,1 \\
\hline 6 & 28,9 & 21,5 & 83,2 & 1,1 & 8,2 & 97,1 & 42 & 18,8 & 87,2 & 0,9 & 13,8 & 92,3 & 36,3 & 26 & 75,8 \\
\hline 7 & 30,2 & 22,6 & 81,6 & 1,2 & 9,2 & 96,4 & 42,8 & 19,2 & 86,7 & 0,9 & 14,3 & 91,7 & 27,5 & 19,7 & 86,1 \\
\hline 8 & 41,5 & 31 & 65,4 & 2,6 & 19,3 & 84,1 & 105,2 & 29,2 & 67,3 & 1,8 & 28,6 & 66,7 & 42,1 & 30,1 & 67,4 \\
\hline 9 & 43 & 31,7 & 62,8 & 2,7 & 20 & 83 & 68,8 & 30,6 & 65,6 & 1,9 & 29,3 & 65,2 & 43,9 & 31,4 & 64,5 \\
\hline 10 & 41,5 & 31 & 65,2 & 2,8 & 21,3 & 80,7 & 63,5 & 28,1 & 70,7 & 1,6 & 25,4 & 73,9 & 40,2 & 28,8 & 70,2 \\
\hline 11 & 27,8 & 20,7 & 84,4 & 2,7 & 20,6 & 82 & 45,4 & 20,4 & 85,1 & 0,9 & 14,2 & 91,9 & 28,7 & 20,6 & 84,8 \\
\hline 12 & 31,4 & 23,4 & 80,2 & 0,5 & 3,8 & 99,4 & 42,7 & 19,2 & 86,8 & 1,4 & 21,5 & 81,2 & 29,2 & 20,9 & 84,3 \\
\hline 13 & 33,2 & 24,8 & 77,8 & 0,9 & 6,7 & 98,1 & 48 & 21,6 & 83,2 & 1,4 & 22,3 & 79,9 & 31,9 & 22,9 & 81,2 \\
\hline 14 & 24,8 & 18,5 & 87,6 & 1,4 & 10,5 & 95,3 & 34 & 15,3 & 91,6 & 0,9 & 14,1 & 91,6 & 23,2 & 16,6 & 90,1 \\
\hline 15 & 26,8 & 20 & 85,5 & 1,5 & 11,5 & 94,4 & 38,9 & 17,5 & 89 & 1 & 15,4 & 90,4 & 25,9 & 18,5 & 87,7 \\
\hline 16 & 31,6 & 23,6 & 79,9 & 0,4 & 2,7 & 99,7 & 33 & 14,8 & 92,1 & 0,9 & 14,1 & 91,9 & 29,4 & 21,1 & 84 \\
\hline 17 & 60,1 & 44,8 & 27,2 & 5,6 & 42,4 & 23,3 & 103,1 & 46,3 & 22,8 & 2,5 & 39,7 & 36,2 & 64,1 & 45,9 & 24,3 \\
\hline 18 & 53,2 & 39,7 & 42,9 & 5 & 37,9 & 38,9 & 92,3 & 41,4 & 38,2 & 2,2 & 33,9 & 53,5 & 57,2 & 40,9 & 39,7 \\
\hline 19 & 70,3 & 52,4 & 0,3 & 6,3 & 47,5 & 4,1 & 116,1 & 52,2 & 2,1 & 3,2 & 49,8 & $-0,7$ & 73,2 & 52,4 & 1,3 \\
\hline 20 & 59,7 & 44,6 & 28 & 5,6 & 42,4 & 23,5 & 102,7 & 46,1 & 23,4 & 2,5 & 39,3 & 37,2 & 63,8 & 45,7 & 24,9 \\
\hline 21 & 32 & 17,7 & 88,1 & 1,5 & 11,2 & 94,7 & 31,7 & 14,3 & 92,7 & 0,8 & 13 & 93,2 & 23 & 16,5 & 90,2 \\
\hline 22 & 25 & 18,6 & 87,4 & 0,5 & 3,6 & 99,4 & 35,4 & 15,9 & 90,9 & 0,8 & 12,9 & 93,2 & 23,9 & 17,1 & 89,5 \\
\hline 23 & 26,4 & 19,7 & 86 & 1,5 & 11,2 & 94,7 & 42,7 & 19,2 & 86,7 & 0,9 & 13,7 & 92,4 & 26,1 & 18,7 & 87,5 \\
\hline
\end{tabular}

Em que: $\mathrm{S}_{\mathrm{yx}}$ e $\mathrm{S}_{\mathrm{yx}} \%$ = significância dos coeficientes da equação e $\mathrm{R}_{\mathrm{aj}}^{2}=$ erro padrão da estimativa em quilos por hectare e percentual.

Na Figura 1 estão ilustrados apenas alguns gráficos dos ajustes feitos para os macronutrientes avaliados nos diferentes compartimentos da biomassa aérea da bracatinga, ilustrando o modelo 19, no qual os resíduos estão distribuídos apenas ao redor da média $\left(181 \mathrm{kgha}^{-1}\right)$ para cálcio.

Os gráficos de resíduos também tiveram comportamento semelhante para todos os modelos testados na biomassa aérea total, no compartimento lenha e copa. Portanto, os mesmos modelos foram selecionados para estimativa de alguns macronutrientes em todos os compartimentos da biomassa aérea. Tal seleção é favorável, tendo em vista garantir o mesmo comportamento do modelo matemático na estimativa dos macronutrientes em todos os compartimentos estudados; fato acentuado nos modelos desenvolvidos para magnésio, nos quais apenas houve mudança no coeficiente de interseção. Os valores dos coeficientes estatísticos, bem como o valor do fator de Meyer (FM) para correção da discrepância logarítmica, dos modelos selecionados para estimativa dos macronutrientes em diferentes compartimentos da biomassa aérea de bracatingais, estão apresentados na Tabela 8.

Todos os modelos selecionados tiveram os coeficientes das equações significativos a $95 \%$ de probabilidade, valores de $\mathrm{R}^{2}$ superiores a $84 \%$ e $\mathrm{S}_{\mathrm{yx}}$ inferiores a $21 \%$, indicando bons ajustes e, consequentemente, uma estimativa acurada dos macronutrientes. Sendo assim, conforme o interesse do produtor, cada equação pode ser aplicada individualmente para estimativa dos nutrientes em diferentes componentes da biomassa, a fim de determinar o que é exportado do sítio durante a exploração da lenha, ou até mesmo para determinação do conteúdo de nutrientes que permanecerão na área (copa). 
Tabela 7. Estatísticas de ajuste e precisão dos modelos ajustados por hectare para a biomassa copa da aérea de povoamentos de bracatinga.

\begin{tabular}{|c|c|c|c|c|c|c|c|c|c|c|c|c|c|c|c|}
\hline \multirow[b]{3}{*}{ Modelos } & \multicolumn{15}{|c|}{ Macronutrientes } \\
\hline & \multicolumn{3}{|c|}{$\mathrm{Ca}$} & \multicolumn{3}{|c|}{ Mg } & \multicolumn{3}{|c|}{$\mathbf{N}$} & \multicolumn{3}{|c|}{$\mathbf{P}$} & \multicolumn{3}{|c|}{$\mathbf{K}$} \\
\hline & Syx & Syx \% & $\mathbf{R}_{\text {aj }}^{2}$ & Syx & Syx \% & $\mathbf{R}_{\text {aj }}^{2}$ & Syx & Syx \% & $\mathbf{R}_{\text {aj }}^{2}$ & Syx & Syx \% & $\mathbf{R}_{\text {aj }}^{2}$ & Syx & Syx \% & $\mathbf{R}_{\text {aj }}^{2}$ \\
\hline 1 & 7,2 & 15,4 & 90,1 & 1,3 & 20,6 & 81,9 & 24,3 & 17,7 & 87,6 & 0,9 & 17,1 & 88,6 & 6,5 & 20,4 & 84,4 \\
\hline 2 & 12,4 & 26,4 & 70,8 & 0,2 & 3,8 & 99,4 & 36,5 & 26,6 & 71,9 & 1,2 & 23,5 & 78,4 & 8,5 & 23,6 & 73,5 \\
\hline 3 & 12,2 & 26 & 71,5 & 0,4 & 6,6 & 98,1 & 36,4 & 26,5 & 72,2 & 1,3 & 23,9 & 77,6 & 6,4 & 20,1 & 82,1 \\
\hline 4 & 12,7 & 27,1 & 69,1 & 1,5 & 23,3 & 76,9 & 38,1 & 27,7 & 69,5 & 1,3 & 25,2 & 75,1 & 6,7 & 20,9 & 80,6 \\
\hline 5 & 12,6 & 26,8 & 69,8 & 1,5 & 23,4 & 76,8 & 37,7 & 27,4 & 70 & 1,3 & 25,2 & 75,1 & 9 & 28,3 & 70,1 \\
\hline 6 & 8,2 & 17,5 & 99,2 & 1,8 & 28,2 & 66,1 & 30,2 & 22 & 80,8 & 0,9 & 17,2 & 88,5 & 6,6 & 20,6 & 84,1 \\
\hline 7 & 8,2 & 17,5 & 99,2 & 0,6 & 9,4 & 96,2 & 30,2 & 22 & 80,8 & 0,9 & 17,6 & 87,9 & 6,6 & 20,8 & 83,8 \\
\hline 8 & 14,4 & 30,7 & 60,5 & 1,2 & 19,3 & 84,1 & 43,1 & 31,4 & 60,9 & 1,6 & 30,1 & 64,5 & 10,2 & 32,1 & 61,4 \\
\hline 9 & 14,5 & 30,8 & 60,1 & 1,2 & 20 & 83 & 43,7 & 31,8 & 59,9 & 1,6 & 30,8 & 62,8 & 10,4 & 32,8 & 59,7 \\
\hline 10 & 14,4 & 30,7 & 60,5 & 1,3 & 21,3 & 80,7 & 37,8 & 27,5 & 70 & 1,4 & 27 & 71,5 & 9,2 & 29,1 & 68,4 \\
\hline 11 & 7,3 & 15,5 & 89,9 & 1,3 & 20,6 & 82 & 24,3 & 17,7 & 87,5 & 0,9 & 17,1 & 88,5 & 6,5 & 20,5 & 84,3 \\
\hline 12 & 31,4 & 23,4 & 80,2 & 0,2 & 3,8 & 99,4 & 36,8 & 26,7 & 71,6 & 1,3 & 23,8 & 77,8 & 8,5 & 26,8 & 73,1 \\
\hline 13 & 12,4 & 26,3 & 70,9 & 0,4 & 6,7 & 98,1 & 36,9 & 26,8 & 71,4 & 1,3 & 24,5 & 76,5 & 8,7 & 27,3 & 72,1 \\
\hline 14 & 8,9 & 19 & 84,8 & 0,7 & 10,5 & 95,3 & 27,3 & 19,9 & 84,3 & 0,9 & 17,3 & 88,3 & 6,7 & 21 & 83,6 \\
\hline 15 & 9,1 & 19,3 & 84,3 & 0,7 & 11,5 & 94,4 & 28 & 20,4 & 83,5 & 1 & 18,3 & 86,8 & 6,9 & 21,8 & 82,3 \\
\hline 16 & 12,3 & 26,1 & 71,3 & 0,2 & 2,7 & 99,7 & 27,3 & 19,9 & 84,3 & 0,9 & 17,3 & 88,3 & 8,5 & 26,8 & 73,2 \\
\hline 17 & 16,7 & 35,6 & 46,8 & 2,7 & 42,4 & 23,3 & 53,1 & 38,6 & 40,7 & 2,1 & 40,8 & 34,8 & 13,4 & 42,1 & 33,8 \\
\hline 18 & 13,7 & 29,2 & 64,1 & 2,4 & 37,9 & 38,9 & 44,9 & 32,6 & 57,7 & 1,8 & 35,1 & 51,7 & 11,6 & 36,5 & 50,1 \\
\hline 19 & 22,9 & 48,9 & $-0,4$ & 3 & 47,5 & 4,1 & 69,3 & 50,4 & $-0,9$ & 2,7 & 50,7 & $-0,7$ & 16,5 & 51,9 & $-0,8$ \\
\hline 20 & 16,4 & 35,1 & 48,4 & 2,6 & 42,4 & 23,5 & 52,5 & 38,2 & 42,1 & 2,1 & 40,5 & 35,9 & 13,4 & 42,1 & 33,8 \\
\hline 21 & 7,3 & 15,7 & 89,7 & 0,7 & 11,2 & 94,7 & 24,8 & 18 & 87,1 & 0,9 & 16,7 & 89,1 & 6,6 & 20,7 & 83,9 \\
\hline 22 & 3,8 & 8,1 & 97,3 & 0,2 & 3,6 & 99,4 & 24,2 & 17,6 & 87,7 & 0,9 & 16,2 & 89,7 & 6,3 & 19,9 & 85,2 \\
\hline 23 & 7,2 & 15,4 & 90 & 0,4 & 6,6 & 98,1 & 24,4 & 17,7 & 87,5 & 0,9 & 16,8 & 89 & 6,4 & 20,3 & 84,6 \\
\hline
\end{tabular}

Em que: $\mathrm{S}_{\mathrm{yx}}$ e $\mathrm{S}_{\mathrm{yx}} \%$ = significância dos coeficientes da equação e $\mathrm{R}_{\mathrm{aj}}^{2}=$ erro padrão da estimativa em quilos por hectare e percentual.

Os valores médios estimados dos macronutrientes nos diferentes componentes da biomassa aérea estão listados na Tabela 9.

A quantidade média de nutrientes estimados na biomassa aérea total nas 261 parcelas dos bracatingais estudados (Tabela 9) foram inferiores, porém, com mesma tendência no ordenamento aos encontrados por Baggio \& Carpanezzi (1997), ao estudarem a exportação dos nutrientes na exploração de bracatingais aos sete anos de idade, nos quais relataram valores quantitativos de macronutrientes na biomassa aérea total em $\mathrm{kg} \mathrm{ha}^{-1}$ para: $\mathrm{N}=493 ; \mathrm{P}=18 ; \mathrm{K}=150 ; \mathrm{Ca}=115$ e $\mathrm{Mg}=68$. Somarriba \& Kass (2001) ao estudarem o fluxo de nutrientes em bracatingais com seis anos de idade na região sul do Brasil em áreas de pousio, encontraram valores totais em $\mathrm{kg} \mathrm{ha}^{-1}$ de 356 para N; 10 para $\mathrm{P} ; 167$ para $\mathrm{K}$; 81 para $\mathrm{Ca}$ e 26 para $\mathrm{Mg}$, quantificando apenas galhos, folhas e árvores mortas caídas no solo.

Nota-se que os valores para o compartimento copa estimados pelos modelos selecionados apresentam uma pequena diferença entre a subtração da estimativa dos modelos de biomassa total e copa, com exceção de magnésio e potássio. Em média, após a exploração da lenha, restaram como remanescentes na área $26 \%$ de Ca, $32 \%$ de $\mathrm{Mg}, 38 \%$ de N, $45 \%$ de P e $19 \%$ de K. Caldeira et al. (2004) encontraram valores de macronutrientes mantidos na área, após a exploração de Acacia mearnsii, aos 2,4 anos de idade, muito acima dos encontrados no 

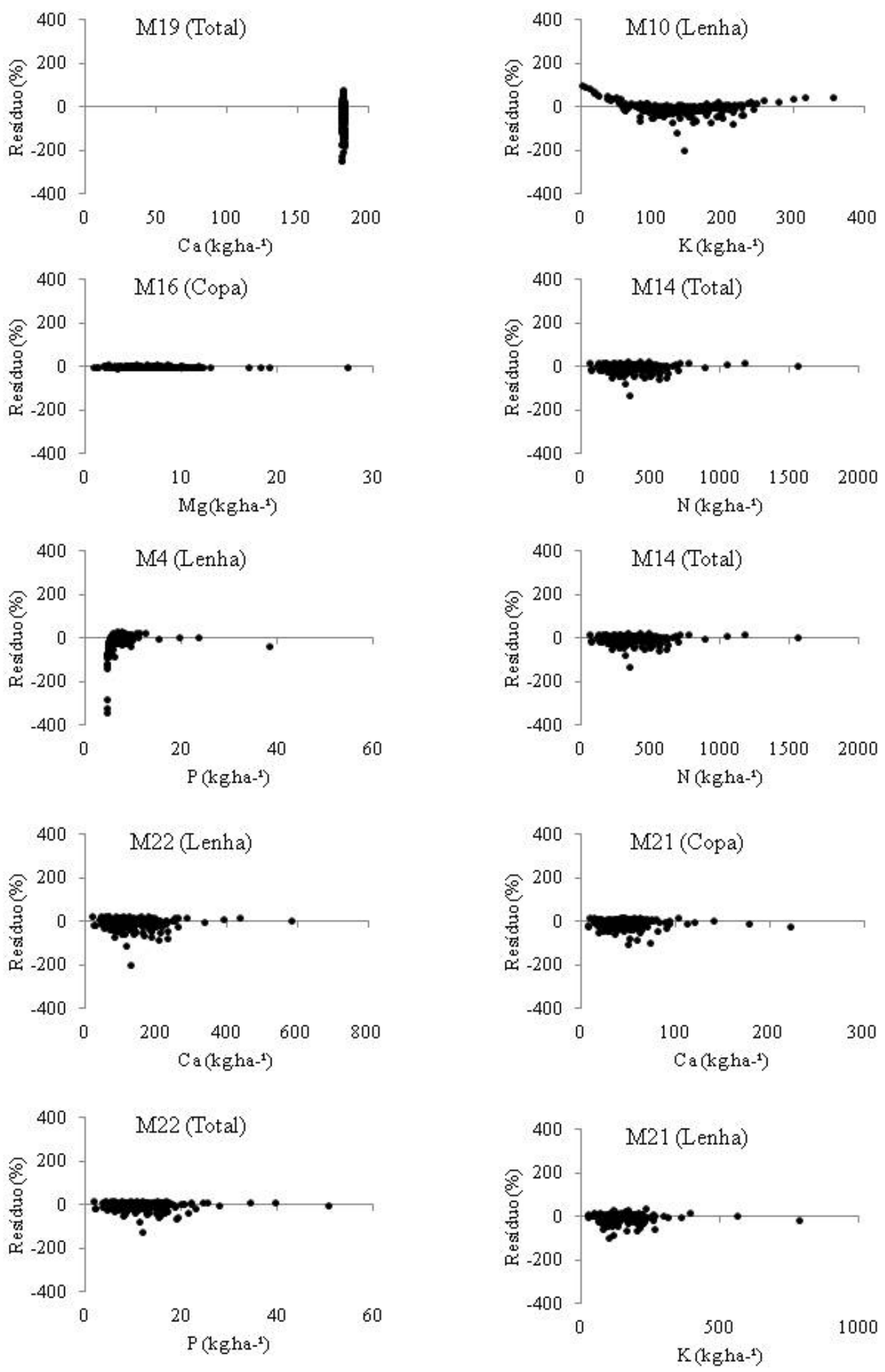

Figura 1. Dispersão dos resíduos de alguns modelos ajustados para estimativa de macronutrientes 
presente trabalho, sendo o percentual de $68,70,74,73$ e 62 para $\mathrm{Ca}, \mathrm{Mg}, \mathrm{N}, \mathrm{P}, \mathrm{K}$, respectivamente. Baggio \& Carpanezzi (1997) relataram valores de $18 \%$ de Ca, $15 \%$ de $\mathrm{Mg}, 11 \%$ de $\mathrm{N}, 9 \%$ de $\mathrm{P}$ e $20 \%$ de K exportados em exploração de bracatingais aos sete anos de idade, valores também distintos aos relatados no presente estudo. Vieira et al. (2011) avaliando o sistema de exploração de Pinus taeda (madeira+casca) aos nove anos de idade, constataram uma remoção de $41,1 \%$ de $\mathrm{Ca}, 46,2 \%$ de $\mathrm{Mg} ; 45,9 \%$ de $\mathrm{K} ; 45,4 \%$ de $\mathrm{P}$ e $40,0 \%$ de $\mathrm{N}$ dos macronutrientes presentes na biomassa total.

Sabe-se que diversos fatores influenciam na quantidade de nutrientes removidos durante o processo de exploração florestal, sendo, portanto, difícil apontar quantidades ótimas de nutrientes remanescentes na área. Para uma melhor visualização dos teores de macronutrientes presentes nos bracatingais ao longo dos anos, os dados foram agrupados em cinco classes de idade com amplitude de três anos, nos quais os valores médios de cada nutriente nas diferentes classes de idade estão ilustrados na Figura 2. Observa-se mostra uma diminuição gradativa no conteúdo de nutrientes ao longo dos anos, com exceção da mudança da classe 1 para 2, que possui valores crescentes, devido ao aumento no porte das árvores. Tal redução é resultado da mortalidade que ocorre nos bracatingais com média de 4.310 indivíduos na classe 1, 2.164 na classe 2, 1.099 na classe 3, 712 na classe 4 e 356 na classe 5 .

Como se pode observar, existe uma grande variação na quantidade de nutrientes mesmo em espécies e idades semelhantes, como, por exemplo, no Eucalyptus. A explicação de tal fato é dada pela quantidade de nutrientes removidos durante o processo de exploração florestal variar conforme o compartimento da planta, idade das árvores, densidade das árvores, biomassa produzida e técnicas e intensidades de exploração aplicadas.

Em diversos trabalhos existentes na literatura (Tabela 10), um gradiente de concentração nos componentes da planta é encontrado, obedecendo a seguinte sequência: folha $>$ casca $>$ ramo $>$ tronco, sendo que, dentro do mesmo compartimento podem existir variações significativas de concentração. Já para a quantidade de nutrientes presentes a sequência: $\mathrm{N}>\mathrm{Ca}>\mathrm{K}>$ $\mathrm{Mg}>\mathrm{P}$ é encontrada em grande parte dos trabalhos publicados, corroborando com os resultados encontrados no presente estudo, podendo também haver alterações em consequência das condições citadas anteriormente.

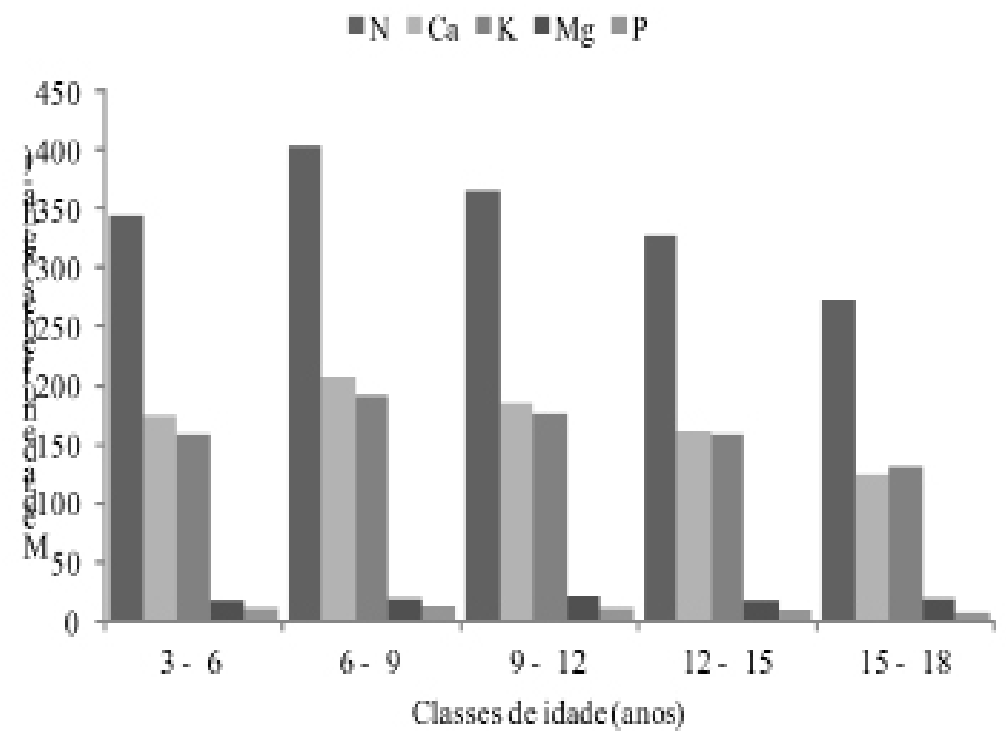

Figura 2. Conteúdo de nutrientes presentes na biomassa aérea total em povoamentos de bracatinga nas diferentes classes de idade. 
Tabela 8. Coeficientes das equações selecionadas para estimativa da quantidade ( $\left.\mathrm{kg} \mathrm{ha}^{-1}\right)$ de macronutrientes presentes na biomassa aérea de bracatingais.

\begin{tabular}{ccccccc}
\hline Nutriente (Modelo) & Biomassa & $\mathbf{B}_{\mathbf{0}}$ & $\mathbf{B}_{\mathbf{1}}$ & $\mathbf{B}_{\mathbf{2}}$ & $\mathbf{B}_{\mathbf{3}}$ & $\mathbf{F M}$ \\
\hline $\mathrm{Ca}(22)$ & Total & 1,69200 & 0,99745 & 0,37786 & - & 1,016 \\
$\mathrm{Ca}(22)$ & Lenha & 1,03497 & 0,99333 & 0,52348 & - & 1,018 \\
$\mathrm{Ca}(11)$ & Copa & 1,25125 & 1,01221 & - & - & 1,012 \\
$\mathrm{Mg}(16)$ & Total & $-2,11911$ & 0,71729 & 0,28278 & - & 1,000 \\
$\mathrm{Mg}(16)$ & Lenha & $-2,50388$ & 0,71729 & 0,28278 & - & 1,000 \\
$\mathrm{Mg}(16)$ & Copa & $-3,26043$ & 0,71729 & 0,28278 & - & 1,000 \\
$\mathrm{~N}(14)$ & Total & 2,12010 & 0,49370 & - & - & 1,011 \\
$\mathrm{~N}(14)$ & Lenha & 1,63719 & 0,49368 & - & - & 1,011 \\
$\mathrm{~N}(11)$ & Copa & 2,34832 & 1,00197 & - & - & 1,017 \\
$\mathrm{P}(22)$ & Total & $-0,83821$ & 0,99626 & 0,29487 & - & 1,010 \\
$\mathrm{P}(22)$ & Lenha & $-1,42724$ & 0,99402 & 0,29293 & - & 1,008 \\
$\mathrm{P}(22)$ & Copa & $-1,64786$ & 0,99893 & 0,29726 & - & 1,014 \\
K (14) & Total & 1,35817 & 0,49577 & - & - & 1,014 \\
K (21) & Lenha & 2,47532 & 0,00826 & $-2,70034$ & 1,05941 & 1,011 \\
K (11) & Copa & 0,91169 & 0,98866 & - & - & 1,025 \\
\hline
\end{tabular}

Tabela 9. Conteúdo médio de macronutrientes nos diferentes componentes da biomassa aérea de povoamentos de Mimosa scabrella.

\begin{tabular}{|c|c|c|c|c|c|}
\hline \multicolumn{6}{|c|}{ Conteúdo de nutriente $\left(\mathrm{kg} \mathrm{ha}^{-1}\right)$} \\
\hline & \multicolumn{5}{|c|}{ Biomassa total } \\
\hline & $\mathrm{Ca}$ & $\mathrm{Mg}$ & $\mathrm{N}$ & $\mathrm{P}$ & K \\
\hline Mínimo & 26,68 & 2,55 & 52,77 & 1,75 & 24,92 \\
\hline Médio & 180,81 & 19,56 & 359,24 & 11,60 & 171,07 \\
\hline \multirow[t]{3}{*}{ Máximo } & 790,05 & 85,21 & 1549,55 & 50,57 & 742,14 \\
\hline & \multicolumn{5}{|c|}{ Biomassa lenha } \\
\hline & $\mathrm{Ca}$ & $\mathrm{Mg}$ & $\mathrm{N}$ & $\mathrm{P}$ & K \\
\hline Mínimo & 19,32 & 1,74 & 32,56 & 0,96 & 21,51 \\
\hline Médio & 133,86 & 13,31 & 221,67 & 6,35 & 139,78 \\
\hline \multirow[t]{3}{*}{ Máximo } & 582,25 & 57,99 & 956,13 & 27,61 & 779,56 \\
\hline & \multicolumn{5}{|c|}{ Biomassa copa } \\
\hline & $\mathrm{Ca}$ & $\mathrm{Mg}$ & $\mathrm{N}$ & $\mathrm{P}$ & K \\
\hline Mínimo & 7,26 & 0,82 & 21,71 & 0,79 & 5,15 \\
\hline Médio & 47,02 & 6,25 & 137,76 & 5,25 & 31,84 \\
\hline Máximo & 208,17 & 27,22 & 601,29 & 22,96 & 136,44 \\
\hline
\end{tabular}


Tabela 10. Valores médios de nutrientes quantificados por diferentes pesquisadores ao longo dos anos para diferentes espécies florestais e idades.

\begin{tabular}{|c|c|c|c|c|c|c|c|}
\hline \multirow[b]{2}{*}{ Espécie } & \multirow[b]{2}{*}{ Idade (anos) } & \multicolumn{5}{|c|}{ Conteúdo médio (kg.ha-1) } & \multirow[b]{2}{*}{ Autor } \\
\hline & & $\mathrm{Ca}$ & Mg & $\mathbf{N}$ & $\mathbf{P}$ & $\mathbf{K}$ & \\
\hline Eucalyptus grandis & 4 & 84,0 & 37,7 & 305,5 & 30,6 & 108,2 & Poggiani et al. (1979) \\
\hline Eucalyptus grandis & 7 & 302,0 & 53,0 & 405,0 & 51,0 & 225,0 & Gonçalves et al. (2008) \\
\hline Eucalyptus saligna & 8 & 186,2 & 41,9 & 218,2 & 28,5 & 176,3 & Poggiani et al. (1983) \\
\hline Eucalyptus globulus & 4 & 506,1 & 67,2 & 235,6 & 18,0 & 230,0 & Schumacher \& Caldeira (2001) \\
\hline Pinus taeda & 8 & 42,4 & 12,2 & 148,4 & 16,8 & 39,5 & Moro et al. (2008) \\
\hline Pinus taeda & 12 & 58,4 & 17,2 & 163,9 & 16,3 & 46,5 & Moro et al. (2008) \\
\hline Pinus taeda & 16 & 79,0 & 23,8 & 184,0 & 16,4 & 55,1 & Moro et al. (2008) \\
\hline Pinus taeda & 20 & 67,0 & 24,0 & 140,0 & 11,7 & 43,2 & Moro et al. (2008) \\
\hline Pinus taeda & 9 & 61,1 & 14,4 & 115,8 & 11,9 & 33,1 & Vieira et al. (2011) \\
\hline Pinus oocarpa & 8 & 77,3 & 24,9 & 270,6 & 18,5 & 133,8 & Castro et al. (1980) \\
\hline Pinus oocarpa & 14 & 103,3 & 26,4 & 239,9 & 16,7 & 131,4 & Castro et al. (1980) \\
\hline Pinus oocarpa & 18 & 123,2 & 37,2 & 330,7 & 19,8 & 151,6 & Castro et al. (1980) \\
\hline Acacia mearnsii & 2,4 & 107,7 & 35,1 & 334,4 & 23,7 & 259,7 & Caldeira et al. (2004) \\
\hline Acacia mangium & 5 & 281,7 & 47,0 & 544,9 & 35,2 & 242,9 & Balieiro et al. (2010) \\
\hline Ilex paraguariensis & 10 a 12 & 201,6 & 142,2 & 384,2 & 37,1 & 318,6 & Berger (2006) \\
\hline Hovenia dulcis & 18 & 1224,0 & 183,1 & 650,0 & 53,5 & 569,3 & Schumacher et al. (2008) \\
\hline Mimosa scabrella & 7 & 128,7 & 49,6 & 483,4 & 13,0 & 268,7 & Baggio \& Carpanezzi (1997) \\
\hline
\end{tabular}

\section{Validação}

Para validação dos modelos selecionados, as estatísticas descritas anteriormente apresentadas e a análise visual dos gráficos de resíduos foram realizadas. As equações selecionadas foram aplicadas em uma base de dados independente (43 parcelas) e as estatísticas de acurácia e precisão estão listadas na Tabela 11. Nota-se que apenas para $\mathrm{N}$ e K no componente copa, os valores de precisão são superiores a $10 \%$ para o resíduo médio absoluto. Os demais valores de resíduo médio absoluto foram inferiores a $10 \%$, sendo similar aos resultados obtidos por Soares et al. (1995) ao selecionar modelos volumétricos. Os valores de acurácia foram baixos, indicando que os modelos selecionados estimaram satisfatoriamente a quantidade de nutrientes nos povoamentos de bracatinga. Na figura 3 estáo apresentados oss gráficos de dispersão dos resíduos para cálcio. Os demais macronutrientes tiveram o mesmo comportamento, com a maioria da distribuição homogênea ao longo da linha de regressão, sem grandes tendências na estimativa, porém, com ligeira superestimativa para valores de área basal inferiores a $10 \mathrm{~m}^{2} \mathrm{ha}^{-1}$. 
Tabela 11. Valores de acurácia e precisão dos modelos selecionados para quantificação de nutrientes na biomassa aérea em povoamentos de Mimosa scabrella.

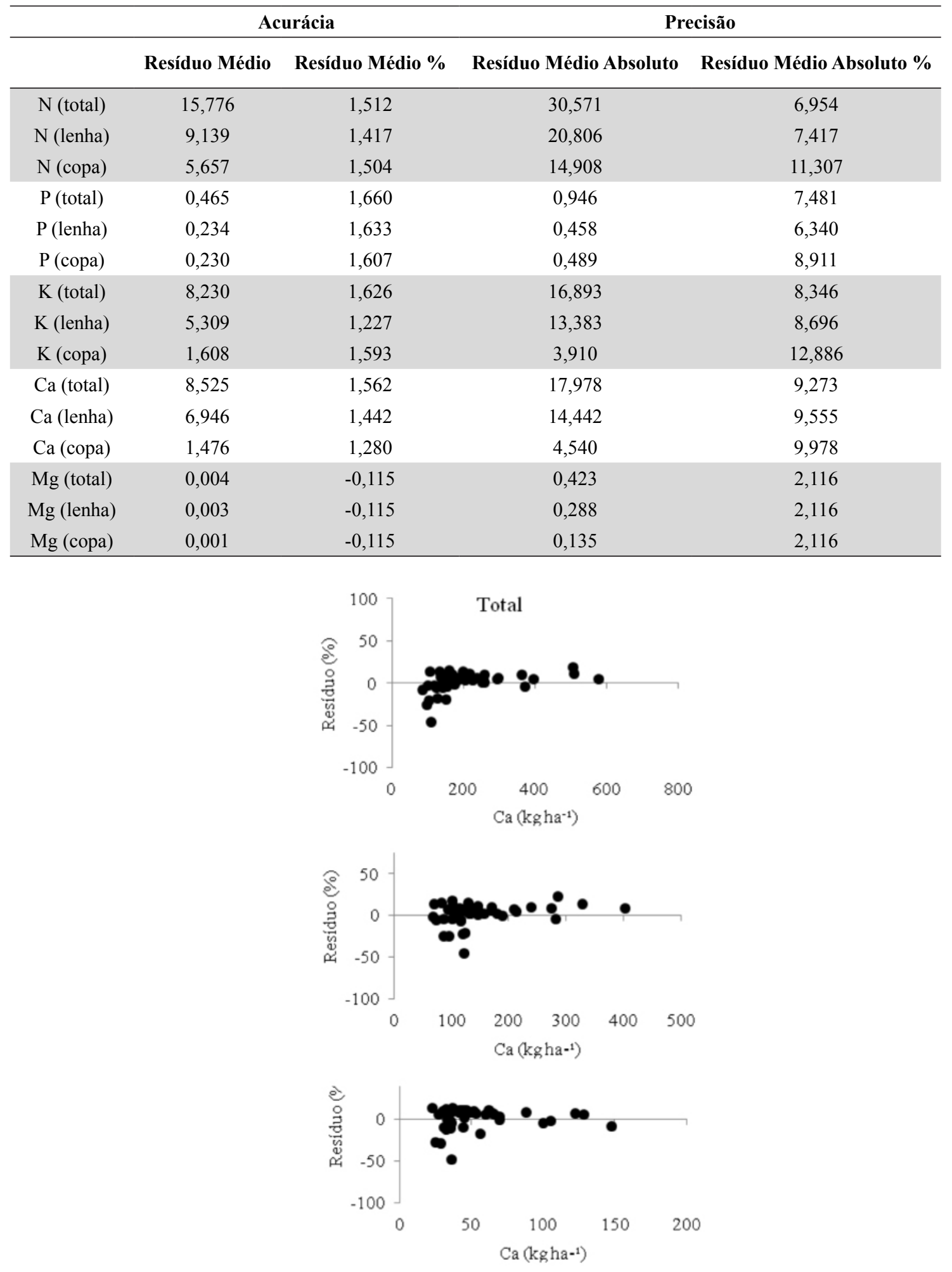

Figura 3. Dispersão dos resíduos dos modelos validados para cálcio. 


\section{Conclusões}

Os modelos selecionados e posteriormente validados se mostraram eficientes para estimativas da quantidade de nutrientes presentes na biomassa aérea de povoamentos de bracatinga, apresentando valores de $\mathrm{R}^{2}$ superiores a $84 \%$ e $\mathrm{S}_{\mathrm{yx}}$ inferiores a $21 \%$.

As equações desenvolvidas para estimativa de macronutrientes por unidade de área envolveram apenas a variável área basal, ou a combinação desta com a variável altura (dominante e média). A medição individual das árvores foi desnecessária, e enfatizouse o potencial da aplicação da relascopia para uma amostragem fácil e precisa em campo.

A quantidade estimada de nutrientes por hectare seguiu a ordem: $\mathrm{N}>\mathrm{Ca}>\mathrm{K}>\mathrm{Mg}>\mathrm{P}$, corroborando com a maioria dos trabalhos encontrados na literatura. Houve uma diminuição gradativa no conteúdo de nutrientes ao longo dos anos, devido à mortalidade acentuada nos bracatingais.

\section{Referências}

AGUIAR, L. P. Modelagem do volume do povoamento da Mimosa scabrella Bentham em bracatingais nativos da região metropolitana de Curitiba. 2006. 83 f. Dissertação (Mestrado em Engenharia Florestal) - Universidade Federal do Paraná, Curitiba.

BAGGIO, A. J.; CARPANEZZI, A. A. Exportação de nutrientes na exploração de bracatingais. Boletim de Pesquisa Florestal, Colombo, n. 34, p. 3-15, jan./jun, 1997.

BALIEIRO, F. C. de; DIAS, L. E.; FRANCO, A. A.; CAMPELLO, E. F. C.; FARIA, S. M. de. Acúmulo de nutrientes na parte aérea, na serapilheira acumulada sobre o solo e decomposição de filódios de Acacia mangium Willd. Ciência Florestal, Santa Maria, RS, v. 14, n. 1, p. 59-65, 2010.

BELlOTE, A. F. J.; SARRUGE, J. R.; HAAG, H. P.; OLIVEIRA, G. D. de. Extração e exportação de nutrientes pelo Eucalyptus grandis Hill ex-Maiden em função da idade: 1- Macronutrientes. IPEF, Piracicaba, SP, n. 20, p. 1-23, 1980.

BERGER, G. Biomassa e nutrientes em plantios de erva mate (Ilex paraguariensis A. St.-Hil.), no município de Nova Prata, RS. 2006. 93 f. Dissertação (Mestrado em Engenharia Florestal), Universidade Federal de Santa Maria, Santa Maria.

CALDEIRA, M. V. W.; SCHUMACHER, M. V.; SANTOS, E. M. dos; TEDESCO, N.; PEREIRA, J. C. Estimativa do conteúdo de nutrientes em povoamento jovem de Acacia mearnsii De Wild. estabelecido na região sul do Brasil. Floresta, Curitiba, v. 29, n. $1 / 2$, p. $53-65,2004$
CALDEIRA, M. V. W.; RONDON NETO, R. M.; SCHUMACHER, M. V.; WATZLAVICK, L. F. Exportação de nutrientes em função do tipo de exploração em um povoamento de Acacia mearnsii De Wild. Floresta e Ambiente, Seropedica, v. 9, n. 1, p. 97-104, 2002.

CARNEIRO, R. M.; ALMEIDA JUNIOR, A. R.; KAGEYAMA, P. Y.; DIAS, I. S. Importância da dormência das sementes na regeneração da bracatinga - Mimosa scabrella Bentham. Piracicaba: IPEF, 1982. 10 p., (IPEF. Circular técnica, 149).

CARPAZEZZI, A. A. Aspectos técnicos da produção de bracatinga. In: OFICINA SOBRE BRACATINGA NO VALE DO RIBEIRA, 2004, Curitiba. Memórias. Colombo: Embrapa Florestas, 2006. p. 39-44. (Embrapa Florestas. Documentos, 134).

CASTRO, C. F. de A.; POGGIANI, F.; NICOLIELO, N. Distribuição da fitomassa e nutrientes em talhões de Pinus oocarpa com diferentes idades. IPEF, n. 20, p. 61-74, 1980.

COUTO, H. T. Z. do; BASTOS, N. L. M.; LACERDA, J. S. de. A amostragem por pontos na estimativa de área basal em povoamentos de Eucalyptus. IPEF, Piracicaba, SP, n. 46, p. 86-95, 1993.

DRAPER, N. R.; SMITH, H. Applied regression analysis. New York: John Wiley \& Sons, 1968. 407 p.

EMBRAPA. Levantamento de reconhecimento dos solos do estado do Paraná. Londrina: EMBRAPA-SNLS/IAPAR, 1984. v. 2. 791 p. (EMBRAPA-SNLS. Boletim de pesquisa, n. 27).

FERREIRA, C. A.; SILVA, H. D. da; REISSMANN, C. B.; BELLOTE, A. F. J.; MARQUES, R. Nutrição de Pinus no Sul do Brasil: diagnóstico e prioridades de pesquisa. Colombo: Embrapa Florestas. 2001. 23 p.

FIGUEIREDO FILHO, A. Estudos de modelos matemáticos para estimar o volume por unidade de área em uma floresta tropical úmida na Amazônia brasileira. 1983. 150 f. Dissertação (Mestrado em Engenharia Florestal) - Setor de Ciências Agrárias, Universidade Federal do Paraná, Curitiba.

GONÇALVES, J. L. de M.; STAPE, J. L.; LACLAU, J. P.; BOUILLET, J. P.; RANGER, J. Assessing the effects of early silvicultural management on long- term site productivity of fast-growing eucalypt plantations: the Brazilian experience. Southern Forests, v. 70, p. 105-118, 2008.

MAACK, R. Geografia física do estado do Paraná. 3. ed. Curitiba: Imprensa Oficial do Paraná, 2002. 440 p.

MACHADO, S. A.; AGUIAR, L. P.; FIGUEIREDO FILHO, A.; KOEHLER, H. S. Modelagem do volume do povoamento para $\mathrm{Mi}$ mosa scabrella Benth. na região metropolitana de Curitiba. Revista Árvore, Viçosa, MG, v. 32, n. 3, p. 465-478, 2008.

MONTGOMERY, D. C.; PECK, E. A. Indroduction to linear regression analysis. 2. ed. New York: J. Wiley, 1992. 527 p.

MORO, L.; FERREIRA, C. A.; SILVA, H. D.; REISSMANN, C. B. Exportação de nutrientes em povoamentos de Pinus taeda L. baseada em volume estimado pelo sistema SISPINUS. Floresta, Curitiba, PR, v. 38, n. 3, 2008. 
POGGIANI, F.; COUTO, H. T. Z. do; SIMÕES, J. W. Aspectos ecológicos das minirotações e do aproveitamento dos resíduos florestais. Piracicaba, SP: IPEF, 1979. 7 p. (IPEF. Circular técnica, 74).

POGGIANI, F.; COUTO, H. T. Z. do; CORRADINI, L.; FAZZIO, E. C. M. Exportação de biomassa e nutrientes através da explotação dos troncos e das copas de um povoamento de Eucalyptus saligna. IPEF, Piracicaba, SP, n. 25, p. 37-39, 1983.

ROSOT, M. A. D. Estudo comparativo de métodos para a avaliação volumétrica por unidade de área $\mathrm{em}$ um povoamento de Pinus taeda L. 1989. 143 f. (Mestrado em Engenharia Florestal) Universidade Federal do Paraná, Curitiba.

SCHUMACHER, M. V.; CALDEIRA, M. V. W. Estimativa da biomassa e do conteúdo de nutrientes de um povoamento de Eucalyptus globulus (Labillardière) sub-espécie maidenii. Ciência Florestal, Santa Maria, RS, v. 11, n. 1, p. 45-53, 2001.

SCHUMACHER, M. V; BRUN, E. J.; ILLANA, V. B.; DISSIUTA, S. I.; AGNE, T. L. Biomassa e nutrientes em um povoamento de $\mathrm{Ho}-$ venia dulcis Thunb., plantado na FEPAGRO Florestas, Santa Maria, RS. Ciência Florestal, Santa Maria, RS, v. 18, n. 1, p. 27-37, 2008.

SCOLFORO, J. R. S. Biometria Florestal: parte I: modelos de regressão lienar e não linear; parte II: modelos de relação hipsométrica, volume, afilamento e peso de matéria seca. Lavras, MG: UFLA/ FAEPE, 2005. $352 \mathrm{p}$.

SOARES, P.; TOMÉ, M.; SKOVSGAARD, J. P.; VANCLAY, J. K. Evaluating a growth model for forest management using continuous forest inventory data. Forest Ecology and Management, Amsterdam, v. 71, n. 3, p. 251-265, 1995.

SOMARRIBA, E.; KASS, D. Estimates of above-ground biomass and nutrient accumulation in Mimosa scabrella fallows in southern Brazil. Agroforestry Systems, Amsterdam, v. 51, n. 2, p. 77-84, 2001.
SILVA, J. de A. Estimativa do volume por hectare e sua composição em povoamentos de Eucalyptus spp. nos cerrados em Minas Gerais e Mato Grosso do Sul. 1979. 170 f. (Mestrado em Engenharia Florestal) - Universidade Federal do Paraná, Curitiba.

SILVA, G. F. da; LEITE, V. R.; CURTO, R. A.; MORA, R.; MARTINS, L. T.; SANTOS, E. M. dos; SOARES, C. P. B. Cuidados com o uso do coeficiente de determinação na análise do ajuste de modelos volumétricos. In: SIMPÓSIO LATINO AMERICANO SOBRE MANEJO FLORESTAL, 4, 2008, Santa Maria, RS. Anais... Santa Maria, RS: UFSM, 2008. v. 2. p. 339-344.

SPURR, S. H. Forest Inventory. New York: The Ronald Press Company. 1952. 476 p.

SULLIVAN, A. D.; CLUTTER, J. L. A simultaneous growth and yield model for loblolly pine. Forest Science, Lawrence, v.18, p. 76-86, 1972.

TÉO, S. J. Quantificação e modelagem do conteúdo de nutrientes na biomassa aérea de bracatinga (Mimosa scabrella Bentham). 2009. 157 f. Dissertação (Mestrado em Engenharia Florestal) - Universidade Federal do Paraná, Curitiba.

TÉO, S. J.; MACHADO, S. A.; FIGUEIREDO FILHO, A.; REISSMANN, C. B. Models for estimating macronutrients in Mimosa scabrella Bentham. Cerne, Lavras, MG, v. 16, n. 3, p. 323-334, 2010.

UNG, C. H.; OUELLET, D. Stand volume tables: application to black spruce stands of Lebel-sur-Quévillon. Forestry Chronicle Ottawa, v. 67, n.6. p. 712-715, 1991.

VANCLAY, J. K.; SKOVSGAARD, J. P. Evaluating forest growth models. Ecological Modelling, Amsterdam, v. 98, n. 1, p. 1-12, 1997.

VIEIRA, M.; SCHUMACHER, M. V.; BONACINA, D. M. Biomassa e nutrientes removidos no primeiro desbaste de um povoamento de Pinus taeda L. em Cambará do Sul, RS. Árvore, Viçosa, MG, v. 35, n. 3, p. 371-379, 2011. 
